\title{
IMMEDIATE COMMUNICATION
}

\section{Targeting the schizophrenia genome: a fast track strategy from GWAS to clinic}

\author{
T Lencz $^{1,2,3}$ and AK Malhotra ${ }^{1,2,3}$
}

The Psychiatric Genomics Consortium-Schizophrenia Workgroup (PGC-SCZ) has recently published a genomewide association study (GWAS) identifying $>100$ genetic loci, encompassing a total of 341 protein-coding genes, attaining genomewide significance for susceptibility to schizophrenia. Given the extremely long time (12-15 years) and expense ( $>\$ 1$ billion) associated with the development of novel drug targets, repurposing of drugs with known and validated targets may be the most expeditious path toward deriving clinical utility from these GWAS findings. In the present study, we examined all genes within loci implicated by the PGC-SCZ GWAS against databases of targets of both approved and registered pharmaceutical compounds. We identified 20 potential schizophrenia susceptibility genes that encode proteins that are the targets of approved drugs. Of these, we prioritized genes/targets that are of clear neuropsychiatric interest and that are also sole members of the linkage disequilibrium block surrounding a PGC-SCZ GWAS hit. In addition to DRD2, 5 genes meet these criteria: CACNA1C, CACNB2, CACNA1I, GRIN2A and HCN1. An additional 20 genes coding for proteins that are the targets of drugs in registered clinical trials, but without approved indications, were also identified. Although considerable work is still required to fully explicate the biological implications of the PGC-SCZ GWAS results, pathways related to these known, druggable targets may represent a promising starting point.

Molecular Psychiatry (2015) 20, 820-826; doi:10.1038/mp.2015.28; published online 14 April 2015

\section{INTRODUCTION}

After years of effort from hundreds of investigators and tens of thousands of DNA samples collected worldwide, the Psychiatric Genomics Consortium-Schizophrenia Workgroup (PGC-SCZ) has recently published a genomewide association study (GWAS), which established a list of $>100$ genetic loci conveying risk for the disorder at conventionally accepted standards of statistical significance. ${ }^{1}$ Although representing a watershed event in psychiatric research, the complexity revealed by the PGC-SCZ results will require considerable further analysis to yield clinically applicable insights. GWAS hits, by their nature, involve broad genomic loci defined by linkage disequilibrium (LD) structure, often containing multiple genes, and do not provide mechanistic insight without further experimentation. ${ }^{2}$ It is noteworthy that relatively few loci from the PGC-SCZ study implicated specific amino acid changes or clearly overlapped gene expression quantitative trait loci, such that many hundreds of genes were potentially implicated by these results.

A primary aim of GWAS is to identify potential targets for pharmaceutical interventions, and the ultimate success of the PGC-SCZ efforts will be judged, in part, on new treatment development. Proof of principle for a potential role of GWAS in target identification was established by an early study demonstrating an association between levels of low-density lipoprotein cholesterol and single-nucleotide polymorphisms (SNPs) within $H M G C R$, a gene that produces the rate-limiting enzyme for cholesterol synthesis. ${ }^{3}$ This enzyme is targeted for inhibition by the statin class of drugs; however, it must be noted that this proof of principle is retrospective, insofar as statins were developed on the basis of biological knowledge developed many years before this association. ${ }^{4}$ Similarly, GWAS for rheumatoid arthritis has yielded a genomewide significant hit in $I L 6 R$, which is the target for tocilizumab, a monoclonal antibody previously approved by the Food and Drug Administration (FDA) for treatment of rheumatoid arthritis. ${ }^{5}$ In this context, it is notable that one PGCSCZ locus included DRD2, encoding the dopamine D2 receptor that is targeted by all effective antipsychotic medications. ${ }^{6}$ Thus, it is reasonable to ask whether any of the other genes at schizophrenia GWAS loci may serve as a target for future development of novel antipsychotic pharmaceuticals.

Given the large number of genes within loci implicated by the PGC-SCZ results, one way to prioritize the search space is to identify those genes which encode proteins that are known to be druggable. On the basis of biochemical principles of solubility and lipophilicity (the so-called 'rule of five ${ }^{\prime}{ }^{7}$ ) it was originally estimated that as many as $15 \%$ of all genes in the human genome may produce proteins that can be bound by orally bioavailable compounds. ${ }^{8,9}$ Recent estimates, based on technical advances and modifications of the rule of five, suggest that the potential for druggability may extend to $>7000$ genes. ${ }^{10}$ In practice, however, the process of validating these targets with compounds that are able to transition from preclinical models to clinical trials remains a major bottleneck in the process of drug development. ${ }^{11}$ Consequently, it has been suggested that more rapid utility from GWAS results may be obtained by the identification of drug/target combinations that have already been validated by preclinical work and have progressed to human clinical trials and/or FDA approval. ${ }^{12}$

Our approach here is based on the notion that the repurposing of approved drugs, or those already in trials for other indications,

'Division of Psychiatry Research, Zucker Hillside Hospital, Glen Oaks, NY, USA; ${ }^{2}$ Center for Psychiatric Neuroscience, Feinstein Institute for Medical Research, Manhasset, NY, USA and ${ }^{3}$ Departments of Psychiatry and Molecular Medicine, Hofstra University School of Medicine, Hempstead, NY, USA. Correspondence: Dr T Lencz or Dr AK Malhotra, Division of Psychiatry Research, Zucker Hillside Hospital, 75-59 263rd Street, Glen Oaks, NY 11004, USA.

E-mail: lencz@lij.edu or malhotra@lij.edu

Received 15 November 2014; revised 10 January 2015; accepted 23 January 2015; published online 14 April 2015 
is the fastest route to clinic. ${ }^{13}$ Such drugs already have known safety profiles and pharmacokinetic data, even if they have failed in generating robust efficacy signal for their original indication. ${ }^{14}$ This approach has been endorsed by recent initiatives of the National Institutes of Health ${ }^{15}$ and the National Institute of Mental Health ${ }^{16}$ and has been an increasing trend in industry as well. ${ }^{17}$ To date, a number of existing compounds have been examined for possible repurposing in schizophrenia, including anti-inflammatory drugs, anti-epileptic drugs and several hormones, ${ }^{18}$ based on pathophysiologic hypotheses with varying levels of empirical support. With the publication of large-scale GWAS data for schizophrenia, it is now timely to utilize this genomic understanding for purposes of drug repositioning.

In the present study, we comprehensively examined all genes at PGC-SCZ GWAS loci against databases of drug targets. The most complete recent survey identified 1030 unique genes $(\sim 5 \%$ of all protein-coding genes in the genome) serving as targets of drugs that are either approved or in registered clinical trials; ${ }^{19}$ this list was compared with the PGC-SCZ list of potential schizophrenia candidate genes to determine the degree of overlap. Then, we characterized the available compound(s) for each druggable candidate gene in terms of mechanism of action and original indication. For this analysis, we supplemented the list of druggable targets with additional sources of publicly available information on registered drug trials and approvals.

\section{MATERIALS AND METHODS}

\section{Candidate genes}

Input for all analyses was derived from the results of the PGC-SCZ study; ${ }^{1}$ a total of 341 protein-coding RefSeq genes as listed in supplementary table 3 of that publication were considered. Briefly, association of $\sim 9.5$ million genetic variants to schizophrenia was examined across 46 case-control cohorts of European ancestry, 3 case-control cohorts of east Asian ancestry and 3 cohorts of trios (two parents and one affected offspring) of European ancestry. SNPs crossing a threshold $P<10^{-6}$ in meta-analysis of these discovery cohorts (comprising $>83000$ subjects) were then tested in a replication cohort of $\sim 1500$ cases and $\sim 66000$ controls of primarily Icelandic ancestry from deCODE. Results were then combined across all $\sim 150000$ subjects, resulting in 128 LD-independent SNPs meeting standard criteria for genomewide significance $\left(P \leqslant 5 \times 10^{-8}\right)$. An associated region was defined by all SNPs in moderately high LD ( $r 2 \geqslant 0.6)$ around each of these 128 top GWAS hits; overlapping or neighboring (within $250 \mathrm{~kb}$ ) regions were merged, resulting in 108 independent loci. All protein-coding genes contained within these loci, or starting within $20 \mathrm{~kb}$ of these loci, were considered as candidate genes for purposes of the present study. In addition, for loci containing no genes, the nearest gene within $500 \mathrm{~kb}$ was considered a candidate.

\section{Identification of drug targets}

The primary source of confirmed druggable targets was the curated list of 1030 genes recently published by Rask-Anderson et al. ${ }^{19}$ This list was developed with publicly available resources including: the DrugBank ${ }^{20}$ database (http://www.drugbank.ca); the Drugs@FDA database (http:// www.accessdata.fda.gov/scripts/cder/drugsatfda/); and the Drugs in Clinical Trials Database (http://www.centerwatch.com). As described by Rask-Anderson et al., ${ }^{19}$ considerable manual curation is required due to lack of uniform nomenclature and data organization available from these primary datasources. Of the 1030 druggable genes, 555 unique genes were identified that serve as targets of approved pharmaceuticals, which they refer to as 'established targets.' An additional $\mathbf{4 7 5}$ genes were targeted by compounds in registered clinical trials, referred to as 'novel targets.' The full list of 1030 drug targets represents $5.06 \%$ of all genes (based on the GENCODE ${ }^{21}$ version 19, July 2013 freeze, which estimates the total number of protein-coding genes in the human genome at 20,345).

\section{Characterization of drug mechanism of action and indication}

To characterize all possible approved and in-trial drugs, we supplemented the list of Rask-Anderson et al.,19 which was based on an April 2013 data freeze, with three additional sources of information: the proprietary
CiteLine database (accessed 1 June 2014); the publicly available DrugBank database $^{20}$ (accessed 20 July 2014); and the Drug-Gene Interaction database $^{10}$ (accessed 20 July 2014). Gene products were only considered to be true drug targets if direct binding had been demonstrated; indirect effects of up- or down-regulation were not included.

\section{RESULTS}

Of the 341 genes on the PGC list, 27 (7.92\%) are drug targets on the Rask-Anderson list. As described in the methods, we supplemented the listings from Rask-Anderson ${ }^{19}$ with updated information from three additional databases, which increased the number of validated drug targets to $40(11.7 \%$ of all candidate genes derived from the PGC-SCZ GWAS). In the absence of mechanistic understanding of the role of GWAS-derived genetic variants in schizophrenia pathophysiology, this relatively large percentage provides preliminary ground for optimism that one or more of these targets may yield an effective treatment.

Next, we sought to characterize drugs targeting genes derived from the PGC-SCZ in terms of FDA status, mechanism of action and primary indication, in order to identify their potential for repurposing. As displayed in Table 1, half of these genes $(n=20)$ encode proteins that are the targets of approved drugs (note that some approvals are from Europe rather than the FDA). Given that we do not know whether specific GWAS-derived variants have upward or downward effects on gene function, it is notable that several of these targets have both agonist and antagonist drugs on the market or under investigation.

In the table, gene targets that are more likely to be relevant to schizophrenia pathophysiology are listed above the thin line. Likelihood of relevance is defined by either of the following characteristics: the gene is targeted by a drug with existing neuropsychiatric indications; or it encodes a protein that is constitutive of a neurotransmitter receptor, ion channel or ion transporter. Also indicated in the table are genes that are sole members of the LD block encompassing a PGC-SCZ GWAS hit (cf. supplementary table 3 in the PGC-SCZ paper ${ }^{1}$ ). Such genes are arguably more likely to be relevant to schizophrenia pathophysiology than other GWAS-nominated genes, given that many of the significant LD blocks in the PGC-SCZ paper contain multiple genes (up to a maximum of 26 genes at a single locus).

In addition to $D R D 2$, five genes are noteworthy insofar as they are the sole genes within an LD block and are likely to be relevant to neuropsychiatric pathophysiology: CACNA1C, CACNB2, CACNA11, GRIN2A and HCN1. These might be considered the 'low-hanging fruit' that are worthy of the most intensive immediate efforts for further research. Arguably, GRIA1 could be added to this list, as it is the nearest gene to an intergenic signal in the PGC-SCZ GWAS. Drugs targeting the protein products of these genes will be considered in greater detail in the discussion section below.

An additional 20 genes without approved indications, but which are the target of drugs that are currently in registered clinical trials appears in Table 2. (Note that NISCH appears in both Tables 1 and 2, with approved agonists and in-trial antagonists.) As in Table 1, targets with neuropsychiatric relevance are listed above the thin line, and genes that are lone members of a GWAS-derived LD block are highlighted. Intriguingly, one gene in Table 2 that meets both of these criteria is GRM3, encoding the metabotropic 3 glutamate receptor. Agonism at this receptor has been the focus of an initially promising drug development effort, ${ }^{22}$ although subsequent large-scale trials were not successful. ${ }^{23-25}$ An antagonist of GRM3 is also the subject of a phase 2 clinical trial for the treatment of depression (NCT01457677). Two other genes targeted by drugs in clinical trials, which are notable for relevance and likelihood, are ATP2A2 and PRKD1. As an adenoassociated virus-1-based gene therapy, mydicar (targeting ATP2A2) may be unwieldy for testing in schizophrenia. ${ }^{26}$ Bryostatin 
Table 1. PGC-SCZ genes that produce proteins which are targets of compounds with approved indications

\begin{tabular}{|c|c|c|}
\hline Gene & Mechanism & Current indications \\
\hline \multirow{2}{*}{$\begin{array}{l}\text { CA14 } \\
\text { CACNA1C/CACNB2 }\end{array}$} & Carbonic anhydrase inhibitor & Glaucoma, diuretic, epilepsy \\
\hline & $\begin{array}{l}\text { L-type calcium channel antagonist } \\
\text { L-type calcium channel activator }\end{array}$ & Hypertension, angina, irritable bowel syndrome \\
\hline CACNA1I & T-type calcium channel antagonist & $\begin{array}{l}\text { Arrnythmia (Ibutilide) } \\
\text { Epilepsy }\end{array}$ \\
\hline CHRM4 & Muscarinic receptor antagonist & Gastrointestinal disease, incontinence \\
\hline \multirow[t]{2}{*}{ CHRNA3/CHRNB4 ${ }^{\mathbf{a}}$} & Nicotinic receptor partial agonist & Smoking cessation \\
\hline & Nicotinic receptor antagonist & Hypertension, smoking cessation \\
\hline \multirow[t]{2}{*}{ DRD2 } & Dopamine receptor antagonist & Schizophrenia, bipolar disorder, nausea \\
\hline & Dopamine receptor agonist & Parkinson's disease \\
\hline \multirow{2}{*}{ GRIA1 } & AMPA receptor antagonist & Epilepsy, anesthesia \\
\hline & AMPA receptor agonist & Cognitive enhancement ${ }^{b}$ \\
\hline GRIN2A & NMDA receptor antagonist & Epilepsy, Alzheimer's disease \\
\hline HCN1 & Sodium channel antagonist & Anginab \\
\hline $\mathrm{NISCH}$ & Imidazoline I1 receptor agonist & Hypertension ${ }^{\mathrm{b}}$ \\
\hline SLC12A4 & Potassium/chloride transporter inhibitor & Diuretic (congestive heart failure) \\
\hline \multirow{7}{*}{$\begin{array}{l}\text { CYP17A } \\
\text { DPP4 } \\
\text { F2 } \\
\text { FURIN } \\
\text { MAPK3 } \\
\text { PTGIS }\end{array}$} & 17,20 lyase inhibitor & Prostate cancer \\
\hline & Dipeptidyl peptidase 4 inhibitor & Type 2 diabetes \\
\hline & Heparin/thrombin stimulant & Hemorrhage, thrombosis \\
\hline & TGF- $\beta$ pro-protein convertase inhibitor & Idiopathic pulmonary fibrosis ${ }^{b}$ \\
\hline & MAP kinase inhibitor & Acute promyelocytic leukemia \\
\hline & Prostacyclin synthase inhibitor & Analgesia (non-steroidal anti-inflammatory) ${ }^{c}$ \\
\hline & Prostacyclin synthase inducer & Hypertension \\
\hline \multicolumn{2}{|r|}{ Complement factor 1 inhibitor } & Hereditary angioedema ${ }^{b}$ \\
\hline
\end{tabular}

Table 2. PGC-SCZ genes that produce proteins which are targets of compounds in clinical trials

\begin{tabular}{|c|c|c|}
\hline Gene & Mechanism & Primary indications \\
\hline ATP2A2 & $\mathrm{Na}+/ \mathrm{K}+$ ATPase inhibition & Heart failure \\
\hline \multirow[t]{2}{*}{ GRM3 } & Metabotropic glutamate receptor 3 agonist & Schizophrenia \\
\hline & Metabotropic glutamate receptor 3 antagonist & Depression \\
\hline $\mathrm{NISCH}$ & Imidazoline I1 receptor antagonist & Peripheral neuropathy \\
\hline PRKD1 & Serine/threonine protein kinase activator & Alzheimer's, cancers (multiple) \\
\hline CD14 & Monoclonal antibody & Immunosuppressant \\
\hline$C D C 25 C$ & Synthetic peptide G2 checkpoint abrogator & Cancer (mesothelioma) \\
\hline$C L U$ & Antisense inhibitor of clusterin & Cancer (lung, breast, prostate) \\
\hline CYP26B1 & Retinoic acid hydroxylase inhibitor & Acne, psoriasis \\
\hline DPYD & Inhibitor of dihydropyrimidine dehydrogenase & Cancer (solid) \\
\hline EGR1 & Transcription factor DNA-decoy (EGR1 inhibitor) & Post-surgical pain \\
\hline$E P H X 2$ & Epoxide hydrolase inhibitor & Hypertension, COPD \\
\hline MMP16 & MMP inhibitor (angiogenesis inhibitor) & Cancer (lung, breast) \\
\hline SMG6 & Telomerase inhibitor & Cancer (multiple) \\
\hline TNFRSF13C & BAFF receptor radioligand & Myeloma/lymphoma \\
\hline & BAFF receptor monoclonal antibody & Immunosuppressant \\
\hline
\end{tabular}

is a partial agonist at multiple protein kinase isoforms (including protein kinase $\mathrm{D}$, the product of $P R K D 1)$, which is being tested for its antineoplastic properties. ${ }^{27}$ Notably, protein kinase $D$ modulates the E-cadherin/ $\beta$-catenin pathway, which is critical for synaptic plasticity. ${ }^{28}$ Although a repurposing of bryostatin may be premature, especially given limited understanding of its pharmacokinetics, this represents a promising avenue for further study. 
Table 3. Results of schizophrenia clinical trials for targets listed in Tables 1 and 2

\begin{tabular}{|c|c|c|c|c|}
\hline \multirow{3}{*}{ CACNA1C/CACNB2 } & Verapamil & Antagonist & Adjunctive & Improved positive $\mathrm{Sx}$ in acute patients ${ }^{59}$ \\
\hline & Nifedipine & Antagonist & Adjunctive & No effects on symptoms in chronic patients ${ }^{61}$ \\
\hline & Nifedipine & Antagonist & Adjunctive & Improved cognition in patients with tardive dyskinesia ${ }^{62}$ \\
\hline CACNA11 & MK-8998 & Antagonist & Monotherapy & Failed trial (active comparator did not separate from placebo) ${ }^{40}$ \\
\hline CHRM4 & Xanomeline & Agonist & Monotherapy & Improved positive and negative symptoms ${ }^{63}$ \\
\hline \multirow[t]{2}{*}{ GRIA1 } & Piracetam & Allosteric+ve & Adjunctive & Improved PANSS compared with haldol+placebo ${ }^{41}$ \\
\hline & CX-516 & Allosteric+ve & Adjunctive & No effect on symptoms or cognition ${ }^{42}$ \\
\hline \multirow[t]{2}{*}{ GRIN2A } & Various & Agonist & Adjunctive & Mixed results; see review de Bartolomeis et al..$^{41}$ and meta-analysis ${ }^{44}$ \\
\hline & Memantine & Antagonist & Adjunctive & $\begin{array}{l}\text { improved negative } \mathrm{Sx}_{i}^{46} \text { improved positive and negative } \mathrm{Sx} ;{ }^{47} \\
\text { no effect on any } \mathrm{x}^{48}\end{array}$ \\
\hline GRM3 & LY2140023 & Agonist & Monotherapy & Successful proof-of-concept trial; ${ }^{22}$ multiple unsuccessful large trials ${ }^{23-25}$ \\
\hline
\end{tabular}

\section{DISCUSSION}

Despite the unparalleled success of GWAS as a method for rapidly advancing knowledge, ${ }^{29}$ questions remain about the potential clinical utility of GWAS findings. ${ }^{30}$ Given the perplexing diversity of findings presented by the PGC-SCZ GWAS, it may seem reasonable to extend similar skepticism to the prospect of translating these results to the clinic. However, our results demonstrate: (1) that the PGC-SCZ results are enriched for validated targets of both approved and registered pharmaceutical compounds; and (2) that amongst these targets, there are several examples of 'low-hanging fruit'-genes that are plausibly connected to schizophrenia pathophysiology, and are relatively likely to be influenced by the SNPs identified by the PGC-SCZ GWAS. Of course, one of the genes meeting criteria for 'low-hanging fruit' is $D R D 2$, which is already well known in the context of schizophrenia treatment. In the paragraphs below, we will examine each of the other top targets in further detail. In addition, in Table 3, we present a summary of clinical trials in schizophrenia with agents that bind to targets in Tables 1 and 2.

Multiple compounds that inhibit voltage-gated L-type calcium channels (VLCC), for which CACNA1C and CACNB2 encode constituent proteins, have been approved for cardiovascular indications. ${ }^{31}$ A few VLCC antagonists have been examined in clinical trials in schizophrenia with mixed results; however, these studies have been small, often poorly controlled, and most commonly involved verapamil, a P-glycoprotein substrate with relatively poor central nervous system permeability. ${ }^{32}$ Results of placebocontrolled trials in schizophrenia are summarized in Table 3; in each of these trials, VLCC antagonists were administered as adjunctive medicaton alongside stable treatment with conventional antipsychotics. Given the converging evidence of two independent GWAS hits targeting VLCC components, as well as the central role of calcium channels in regulating neurotransmitter release and neuronal gene transcription, revisiting this class of agents (especially dihydropyridines such as nimodipine, nifedipine and isradipine) should be a high priority for the field. Although there is active investigation of calcium channel blockers in bipolar disorder, ${ }^{33}$ there is currently just one registered clinical trial of a calcium channel blocker in schizophrenia, testing the role of isradipine as a potential adjunctive treatment for cognitive dysfunction (NCT01658150). At the same time, caution must be exercised regarding unavoidable cardiovascular effects of calcium channel blockers, given the predominance of CACNA1C VLCCs in the periphery relative to the central nervous system. ${ }^{34}$
One recent study has suggested that the CACNA1C risk allele downregulates expression of the gene, ${ }^{35}$ raising the possibility that antipsychotic effect might require calcium channel activation, rather than inhibition. Ibutilide, a compound approved for atrial fibrillation, is thought to act via calcium channel activation, insofar as it is blocked in vitro by nifedipine. ${ }^{36}$ However, its relative activity at the VLCC in vivo is controversial. ${ }^{37}$ Determination of the direction of allelic effects at CACNA1C is an urgent priority; in contrast to the post-mortem gene expression study mentioned immediately above, ${ }^{35}$ a recent investigation of induced neurons derived from human fibroblasts of subjects with varying CACNA1C genotypes reported that the risk allele results in higher levels of gene expression. ${ }^{38}$

An argument for urgency can also be made for the T-type calcium channel (CACNA1I), which is targeted by the FDAapproved anticonvulsant zonisamide. Unfortunately, zonisamide has been found to have potential psychotogenic and other deleterious cognitive and psychiatric effects, ${ }^{39}$ suggesting the possibility that agonism of T-type channels may be a more advantageous approach. However, to our knowledge, no activators of this channel are approved or are in clinical trials. A novel T-type calcium channel antagonist, MK-8998, was the subject of a recently reported failed trial, in which the active comparator (olanzapine) did not separate from placebo. ${ }^{40}$ Given that no conclusions can be drawn from such a trial, additional testing of this compound is warranted.

The potential association of schizophrenia with variants at GRIN2A (encoding an N-methyl-D-aspartate (NMDA) receptor subunit) is consistent with the field's longstanding interest in the psychotomimetic properties of NMDA antagonists. Direct and indirect NMDA agonists have been widely studied as potential adjunctive treatments, primarily to ameliorate cognitive deficits and negative symptoms (for example, avolition, alogia and affective flattening) associated with schizophrenia, with mixed results (see review de Bartolomeis et al. ${ }^{41}$ ). Curiously, large multicenter controlled trials ${ }^{42,43}$ have been generally negative for NMDA glycine-site agonists such as glycine, D-serine and D-cycloserine, yet meta-analyses have indicated statistically significant effects of the class as a whole, especially sarcosine. ${ }^{44}$ Initial promising results for the novel glycine transport inhibitor, bitopertin ${ }^{45}$ have not been replicated in large-scale phase III trials. It is possible that this conflicting pattern of results may be indicative of subgroups of patients, perhaps genetically defined, with varying response to NMDA agents. However, this speculative pharmacogenetic 
hypothesis would require rigorous comparison of patients with and without the PGC-SCZ GRIN2A risk allele.

Counterintuitively, the NMDA antagonist memantine (approved for use in Alzheimer's) may have therapeutic properties at low doses due to its rapid off-set of binding and voltage dependence. Clinical trials in schizophrenia have demonstrated mixed results with some evidence of improvement of negative symptoms. ${ }^{46-48}$

Glutamate transmission is also implicated by the potential association with GRIA1, which encodes a subunit of the a-amino3-hydroxy-5-methyl-4-isoxazolepropionic acid-type ionotropic glutamate receptor. It has been demonstrated that this receptor is critical to short-term habituation, which is deficient in gria 1 knockout mice; these knockouts demonstrate a form of aberrant salience proposed as a model for delusional symptomatology in schizophrenia. ${ }^{49}$ Consequently, allosteric modulators that serve to activate a-amino-3-hydroxy-5-methyl-4-isoxazolepropionic acid receptors, including ampakines and members of the racetam family, may have potential for the treatment of schizophrenia. One small study conducted in Iran has provided preliminary evidence for greater reduction of Positive and Negative Syndrome Scale scores in patients treated with piracetam in combination with haloperidol, compared with haloperidol plus placebo. ${ }^{50}$ However, another study failed to show any efficacy for a novel ampakine (CX516) as an adjunctive agent for either cognitive deficits or clinical symptoms of schizophrenia. ${ }^{51}$ Notably, aniracetam is approved in Europe for the treatment of cognitive deficits associated with Alzheimer's disorder.

HCN1 encodes a voltage-gated potassium/sodium channel, strongly expressed in the dendrites of cortical and hippocampal pyramidal cells. ${ }^{52}$ This channel has been implicated as a pacemaker regulating working memory function, making it an attractive target for schizophrenia treatment. ${ }^{53}$ However, the HCN1 antagonist ivabradine, approved in Europe for angina, does not cross the blood-brain barrier. Nevertheless, the genetic association should serve to bolster research on existing agents that may have indirect effects on HCN1 activity, including lamotragine and gabapentin.

This brief survey only touches on the most promising candidates in Table 1, as defined by statistical specificity of PGC-SCZ GWAS results and biological properties of the targets. We encourage follow-up genetic and biological research for each of the 40 listed targets; for example, Table 3 demonstrates that other neurotransmitter receptors, including both muscarinic and nicotinic cholinergic subtypes implicated at complex (multigenic) PGC-SCZ GWAS loci, have been targets of novel treatment development in schizophrenia. (In this context, it is noteworthy that clozapine and olanzapine also demonstrate binding at the M4 muscarinic receptor, ${ }^{54}$ and preclinical research on more selective M4 agents is well advanced. ${ }^{55}$ ) Initial research necessarily must be focused on definitively establishing that the statistical GWAS signal functionally implicates the specified gene of interest, and in which direction (up- or down-regulation) the risk allele functions. The absence of this information is the greatest limitation in our ability to translate GWAS hits into clinical targets. In this regard, data emerging from the new NIMH-funded PsychENCODE project (RFA-MH-14-020), designed to identify non-coding functional genomic elements in brain tissue, may be especially useful.

It is also important to note that our survey is limited to direct effects on targeted genes; future pathway analyses may greatly enhance our ability to exploit the results of GWAS for purposes of target identification. A key example of the utility of such an approach is provided by a recent large-scale GWAS meta-analysis in rheumatoid arthritis, which was able to use protein-protein interaction networks to retrospectively link GWAS hits with a wide variety of existing treatments. ${ }^{56}$ Unfortunately, preliminary pathway analysis conducted by the PGC was unable to identify significantly enriched biological pathways. ${ }^{1}$ Moreover, prospective use of interactome analysis presents the challenge of exponentially increasing potential targets.
It has been argued that the utility of GWAS is limited by the small effect size of GWAS-identified genetic variants on disease phenotypes. Although small effect sizes do mitigate the utility of GWAS for clinical diagnostic purposes, the size of the detected effects does not invalidate GWAS as a tool for identification of relevant biological insights. ${ }^{2}$ For example, D2 antagonists are powerful antipsychotic agents, despite the fact that the risk allele at the PGC-SCZ locus containing DRD2 conveys an odds ratio of only 1.08 , and is ranked 35th on the list of GWAS hits in order of statistical strength of association. Similarly, the efficacy of statins in reducing cholesterol is not proportional to the effect size on cholesterol levels of the HMGCR variant identified by GWAS. ${ }^{3,12}$ A large-scale review recently demonstrated that each copy of the $G$ allele at the HMGCR variant rs17238484 is associated with a mean $0.06 \mathrm{mmoll}^{-1}$ lower value of low-density lipoprotein cholesterol, whereas statin treatment results in a mean low-density lipoprotein reduction of $0.92 \mathrm{mmol} \mathrm{I}^{-1}$. $^{-1}$ In this context, genetic variation and pharmacologic manipulation can be seen as two separate mechanisms for altering the same biological target.

The complexity of the PGC-SCZ results still reminds us that schizophrenia is a highly heterogeneous disorder, and it is unlikely that any single-treatment target or strategy will be efficacious across all, or even the majority, of patients. The mixed results of studies already conducted for these targets, as listed in Table 3, suggest that expected outcomes may be subtle or variable across different samples. Therefore, GWAS-nominated genetic variants should be utilized in clinical research as potential pharmacogenetic moderators of treatment response, in studies of established dopaminergic agents as well as any novel or repurposed compounds.

With these limitations in mind, intensive research into the above-listed targets represents a potential fast track toward novel treatments for schizophrenia. Existing compounds, as listed in Tables 1, 2, 3, overcome a series of obstacles that currently hamper psychiatric drug development: (1) the lengthy time necessary for the drug development process (a dozen years or more from target identification to clinical validation); (2) the lack of access to affected tissue to test target engagement; (3) the limitations of animal models of psychiatric disease; and (4) the retreat of investment in psychopharmacology by the pharmaceutical industry. ${ }^{13}$

\section{CONFLICT OF INTEREST}

Dr Lencz declares no conflict of interest. Dr Malhotra serves on the advisory boards of Genomind, LLC and FORUM Pharmaceuticals.

\section{ACKNOWLEDGMENTS}

This work was supported in part by the National Institutes of Health (R01 MH095458) and the Brain \& Behavior Research Foundation.

\section{REFERENCES}

1 Schizophrenia Working Group of the Psychiatric Genomics Consortium. Biological insights from 108 schizophrenia-associated genetic loci. Nature 2014; 511: 421-427.

2 Plenge RM, Scolnick EM, Altshuler D. Validating therapeutic targets through human genetics. Nat Rev Drug Discov 2013; 12: 581-594.

3 Kathiresan S, Melander O, Guiducci C, Surti A, Burtt NP, Rieder MJ et al. Six new loci associated with blood low-density lipoprotein cholesterol, high-density lipoprotein cholesterol or triglycerides in humans. Nat Genet 2008; 40: 189-197.

4 Endo A. The discovery and development of HMG-CoA reductase inhibitors. J Lipid Res 1992; 33: 1569-1582.

5 Okada Y. From the era of genome analysis to the era of genomic drug discovery: a pioneering example of rheumatoid arthritis. Clin Genet 2014; 86: 432-440.

6 Kapur S, Mamo D. Half a century of antipsychotics and still a central role for dopamine D2 receptors. Prog Neuropsychopharmacol Biol Psychiatry 2003; 27: 1081-1090. 
7 Lipinski CA, Lombardo F, Dominy BW, Feeney PJ. Experimental and computational approaches to estimate solubility and permeability in drug discovery and development settings. Adv Drug Deliv Rev 2001; 46: 3-26.

8 Hopkins AL, Groom CR. The druggable genome. Nat Rev Drug Discov 2002; 1: 727-730.

9 Russ AP, Lampel S. The druggable genome: an update. Drug Discov Today 2005; 10: $1607-1610$.

10 Griffith M, Griffith OL, Coffman AC, Weible JV, McMichael JF, Spies NC et al. DGIdb: mining the druggable genome. Nat Methods 2013; 10: 1209-1210.

11 Scannell JW, Blanckley A, Boldon H, Warrington B. Diagnosing the decline in pharmaceutical R\&D efficiency. Nat Rev Drug Discov 2012; 11: 191-200.

12 Sanseau P, Agarwal P, Barnes MR, Pastinen T, Richards JB, Cardon LR, Mooser V. Use of genome-wide association studies for drug repositioning. Nat Biotechnol 2012; 30: 317-320.

13 Institute of Medicine. Drug Repurposing and Repositioning: Workshop Summary. The National Academies Press: Washington DC, USA, 2014.

14 Ashburn TT, Thor KB. Drug repositioning: identifying and developing new uses for existing drugs. Nat Rev Drug Discov 2004; 3: 673-683.

15 Collins FS. Reengineering translational science: the time is right. Sci Transl Med 2011; 3: $90 \mathrm{~cm} 17$.

16 Insel TR. Next-generation treatments for mental disorders. Sci Transl Med 2012; 4: 155 ps19.

17 Jin G, Wong ST. Toward better drug repositioning: prioritizing and integrating existing methods into efficient pipelines. Drug Discov Today 2014; 19: 637-644.

18 Bumb JM, Enning F, Leweke FM. Repurposed drugs for the treatment of schizophrenia and bipolar disorders. Curr Top Med Chem 2013; 13: 2364-2385.

19 Rask-Andersen M, Masuram S, Schiöth HB. The druggable genome: evaluation of drug targets in clinical trials suggests major shifts in molecular class and indication. Annu Rev Pharmacol Toxicol 2014; 54: 9-26.

20 Law V, Knox C, Djoumbou Y, Jewison T, Guo AC, Liu Y et al. DrugBank 4.0: shedding new light on drug metabolism. Nucleic Acids Res 2014; 42: D1091-D1097.

21 Harrow J, Frankish A, Gonzalez JM, Tapanari E, Diekhans M, Kokocinski F et al. GENCODE: the reference human genome annotation for The ENCODE Project. Genome Res 2012; 22: 1760-1774.

22 Patil ST, Zhang L, Martenyi F, Lowe SL, Jackson KA, Andreev BV et al. Activation of mGlu2/3 receptors as a new approach to treat schizophrenia: a randomized phase 2 clinical trial. Nat Med 2007; 13: 1102-1107.

23 Kinon BJ, Zhang L, Millen BA, Osuntokun OO, Williams JE, Kollack-Walker S et al. A multicenter, inpatient, phase 2, double-blind, placebo-controlled dose-ranging study of LY2140023 monohydrate in patients with DSM-IV schizophrenia. J Clin Psychopharmacol 2011; 31: 349-355.

24 Stauffer VL, Millen BA, Andersen S, Kinon BJ, Lagrandeur L, Lindenmayer JP et al. Pomaglumetad methionil: no significant difference as an adjunctive treatment for patients with prominent negative symptoms of schizophrenia compared to placebo. Schizophr Res 2013; 150: 434-441.

25 Adams DH, Zhang L, Millen BA, Kinon BJ, Gomez JC. Pomaglumetad methionil (LY2140023 monohydrate) and aripiprazole in patients with schizophrenia: a phase 3, multicenter, double-blind comparison. Schizophr Res Treatment 2014; 2014: 758212 .

26 Hajjar RJ, Zsebo K, Deckelbaum L, Thompson C, Rudy J, Yaroshinsky A et al. Design of a phase $1 / 2$ trial of intracoronary administration of AAV1/SERCA2a in patients with heart failure. J Card Fail 2008; 14: 355-367.

27 Clamp A, Jayson GC. The clinical development of the bryostatins. Anticancer Drugs 2002; 13: 673-683.

28 Sun MK, Alkon DL. Bryostatin-1: pharmacology and therapeutic potential as a CNS drug. CNS Drug Rev 2006; 12: 1-8.

29 Welter D, MacArthur J, Morales J, Burdett T, Hall P, Junkins $\mathrm{H}$ et al. The NHGRI GWAS Catalog, a curated resource of SNP-trait associations. Nucleic Acids Res 2014; 42: D1001-D1006.

30 Manolio TA. Bringing genome-wide association findings into clinical use. Nat Rev Genet 2013; 14: 549-558.

31 Triggle DJ. L-type calcium channels. Curr Pharm Des 2006; 12: 443-457.

32 Hollister LE, Trevino ES. Calcium channel blockers in psychiatric disorders: a review of the literature. Can J Psychiatry 1999; 44: 658-664.

33 Gitlin M. Treatment-resistant bipolar disorder. Mol Psychiatry 2006; 11: 227-240.

34 Casamassima F, Hay AC, Benedetti A, Lattanzi L, Cassano GB, Perlis RH. L-type calcium channels and psychiatric disorders: a brief review. Am J Med Genet B Neuropsychiatr Genet 2010; 153B: 1373-1390.

35 Gershon ES, Grennan K, Busnello J, Badner JA, Ovsiew F, Memon S et al. A rare mutation of CACNA1C in a patient with bipolar disorder, and decreased gene expression associated with a bipolar-associated common SNP of CACNA1C in brain. Mol Psychiatry 2014; 19: 890-894.

36 Lee KS, Lee EW. Ionic mechanism of ibutilide in human atrium: evidence for a drug-induced $\mathrm{Na}+$ current through a nifedipine inhibited inward channel. J Pharmacol Exp Ther 1998; 286: 9-22.
37 Wood MA, Gilligan DM, Brown-Mahoney C, Nematzadeh F, Stambler BS, Ellenbogen KA. Clinical and electrophysiologic effects of calcium channel blockers in patients receiving ibutilide. Am Heart J 2002; 143: 176-180.

38 Yoshimizu T, Pan JQ, Mungenast AE, Madison JM, Su S, Ketterman J et al. Functional implications of a psychiatric risk variant within CACNA1C in induced human neurons. Mol Psychiatry 2015; 20: 162-169.

39 McElroy SL, Winstanley E, Mori N, Martens B, McCoy J, Moeller D et al. A randomized, placebo-controlled study of zonisamide to prevent olanzapine-associated weight gain. J Clin Psychopharmacol 2012; 32: 165-172.

40 Egan MF, Zhao X, Smith A, Troyer MD, Uebele VN, Pidkorytov V et al. Randomized controlled study of the T-type calcium channel antagonist MK-8998 for the treatment of acute psychosis in patients with schizophrenia. Hum Psychopharmacol 2013; 28: 124-133.

41 de Bartolomeis A, Sarappa C, Magara S, lasevoli F. Targeting glutamate system for novel antipsychotic approaches: relevance for residual psychotic symptoms and treatment resistant schizophrenia. Eur J Pharmacol 2012; 682: 1-11.

42 Buchanan RW, Javitt DC, Marder SR, Schooler NR, Gold JM, McMahon RP et al. The Cognitive and Negative Symptoms in Schizophrenia Trial (CONSIST): the efficacy of glutamatergic agents for negative symptoms and cognitive impairments. Am J Psychiatry 2007; 164: 1593-1602.

43 Weiser M, Heresco-Levy U, Davidson M, Javitt DC, Werbeloff N, Gershon AA et al. A multicenter, add-on randomized controlled trial of low-dose d-serine for negative and cognitive symptoms of schizophrenia. J Clin Psychiatry 2012; 73: e728-e734.

44 Singh SP, Singh V. Meta-analysis of the efficacy of adjunctive NMDA receptor modulators in chronic schizophrenia. CNS Drugs 2011; 25: 859-885.

45 Umbricht D, Alberati D, Martin-Facklam M, Borroni E, Youssef EA, Ostland M et al. Effect of bitopertin, a glycine reuptake inhibitor, on negative symptoms of schizophrenia: a randomized, double-blind, proof-of-concept study. JAMA Psychiatry 2014; 71: 637-646.

46 Rezaei F, Mohammad-Karimi M, Seddighi S, Modabbernia A, Ashrafi M, Salehi B et al. Memantine add-on to risperidone for treatment of negative symptoms in patients with stable schizophrenia: randomized, double-blind, placebocontrolled study. J Clin Psychopharmacol 2013; 33: 336-342.

47 de Lucena D, Fernandes BS, Berk M, Dodd S, Medeiros DW, Pedrini M et al. Improvement of negative and positive symptoms in treatment-refractory schizophrenia: a double-blind, randomized, placebo-controlled trial with memantine as add-on therapy to clozapine. J Clin Psychiatry 2009; 70: 1416-1423.

48 Lieberman JA, Papadakis K, Csernansky J, Litman R, Volavka J, Jia XD et al. MEMMD-29 Study Group. a randomized, placebo-controlled study of memantine as adjunctive treatment in patients with schizophrenia. Neuropsychopharmacology 2009; 34: 1322-1329.

49 Barkus C, Sanderson DJ, Rawlins JN, Walton ME, Harrison PJ, Bannerman DM. What causes aberrant salience in schizophrenia? A role for impaired short-term habituation and the GRIA1 (GluA1) AMPA receptor subunit. Mol Psychiatry 2014; 19: $1060-1070$.

50 Noorbala AA, Akhondzadeh S, Davari-Ashtiani R, Amini-Nooshabadi H. Piracetam in the treatment of schizophrenia: implications for the glutamate hypothesis of schizophrenia. J Clin Pharm Ther 1999; 24: 369-374.

51 Goff DC, Lamberti JS, Leon AC, Green MF, Miller AL, Patel J et al. A placebocontrolled add-on trial of the Ampakine, CX516, for cognitive deficits in schizophrenia. Neuropsychopharmacology 2008; 33: 465-472.

52 Tsay D, Dudman JT, Siegelbaum SA. HCN1 channels constrain synaptically evoked $\mathrm{Ca} 2+$ spikes in distal dendrites of CA1 pyramidal neurons. Neuron 2007; 56: 1076-1089.

53 Arnsten AF. Prefrontal cortical network connections: key site of vulnerability in stress and schizophrenia. Int J Dev Neurosci 2011; 29: 215-223.

54 Bymaster FP, Felder CC, Tzavara E, Nomikos GG, Calligaro DO, Mckinzie DL. Muscarinic mechanisms of antipsychotic atypicality. Prog Neuropsychopharmacol Biol Psychiatry 2003; 27: 1125-1143.

55 Kruse AC, Kobilka BK, Gautam D, Sexton PM, Christopoulos A, Wess J. Muscarinic acetylcholine receptors: novel opportunities for drug development. Nat Rev Drug Discov 2014; 13: 549-560.

56 Okada Y, Wu D, Trynka G, Raj T, Terao C, Ikari K et al. Genetics of rheumatoid arthritis contributes to biology and drug discovery. Nature 2014; 506: 376-381.

57 Swerdlow DI, Preiss D, Kuchenbaecker KB, Holmes MV, Engmann JE, Shah T et al. HMG-coenzyme A reductase inhibition, type 2 diabetes, and bodyweight: evidence from genetic analysis and randomised trials. Lancet 2014; 385: 351-361.

58 Grebb JA, Shelton RC, Taylor EH, Bigelow LB. A negative, double-blind, placebocontrolled, clinical trial of verapamil in chronic schizophrenia. Biol Psychiatry 1986; 21: 691-694.

59 Price WA. Antipsychotic effects of verapamil in schizophrenia. Hillside J Clin Psychiatry 1987; 9: 225-230.

60 Yamada K, Kanba S, Ashikari I, Ohnishi K, Yagi G, Asai M. Nilvadipine is effective for chronic schizophrenia in a double-blind placebo-controlled study. J Clin Psychopharmacol 1996; 16: 437-439. 
61 Suddath RL, Straw GM, Freed WJ, Bigelow LB, Kirch DG, Wyatt RJ. A clinical trial of nifedipine in schizophrenia and tardive dyskinesia. Pharmacol Biochem Behav 1991; 39: 743-745.

62 Schwartz BL, Fay-McCarthy M, Kendrick K, Rosse RB, Deutsch SI. Effects of nifedipine, a calcium channel antagonist, on cognitive function in schizophrenic patients with tardive dyskinesia. Clin Neuropharmacol 1997; 20: 364-370.

63 Shekhar A, Potter WZ, Lightfoot J, Lienemann J, Dubé S, Mallinckrodt C et al. Selective muscarinic receptor agonist xanomeline as a novel treatment approach for schizophrenia. Am J Psychiatry 2008; 165: 1033-1039.

64 Kishi T, Iwata N. Varenicline for smoking cessation in people with schizophrenia: systematic review and meta-analysis. Eur Arch Psychiatry Clin Neurosci 2014 epub ahead of print.

65 Roh S, Hoeppner SS, Schoenfeld D, Fullerton CA, Stoeckel LE, Evins AE. Acute effects of mecamylamine and varenicline on cognitive performance in non-

smokers with and without schizophrenia. Psychopharmacology (Berl) 2014; 231 765-775.

66 Sacco KA, Termine A, Dudas MM, Seyal AA, Allen TM, Vessicchio JC, Wexler BE, George TP. Neuropsychological deficits in nonsmokers with schizophrenia: effects of a nicotinic antagonist. Schizophr Res 2006; 85: 213-221.

(7) $\Theta$ This work is licensed under a Creative Commons Attributioncc) $\Theta_{\mathrm{BY}} \mathrm{ND}_{\mathrm{ND}}$ NonCommercial-NoDerivs 4.0 International License. The images or other third party material in this article are included in the article's Creative Commons license, unless indicated otherwise in the credit line; if the material is not included under the Creative Commons license, users will need to obtain permission from the license holder to reproduce the material. To view a copy of this license, visit http:// creativecommons.org/licenses/by-nc-nd/4.0/ 